\title{
Six sigma based exponentially weighted moving average control chart
}

\author{
R. Radhakrishnan and P. Balamurugan ${ }^{1}$ \\ PSG College of Arts and Science, Coimbatore-641 014, TN, India \\ ${ }^{1}$ The Kavery Engineering College, Salem-636 453, TN, India \\ rkrishnan_cbe@yahoo.com,pbalamurugan_stat@yahoo.com
}

\begin{abstract}
A control chart is a statistical device used for the study and control of repetitive process. Shewhart (1931) of bell telephone laboratories suggested control charts based on the 3 sigma limits. Now the companies started applying 6 sigma initiatives in their manufacturing process, which results in lesser number of defects, are focused in identifying the causes due to assignable causes of variation. The companies practicing 6 sigma initiatives is expected to produce 3.4 or less number of defects per million opportunities, a concept suggested by Motorola (1980). If the companies practicing 6 sigma initiatives use the control limits suggested by Shewhart, then no point fall outside the control limits because of reduced variation. In this paper an attempt is made to construct a 6 sigma based exponentially weighted moving average control chart specially designed for the companies adopting 6 sigma initiatives in their organization. Suitable table is also constructed and presented for the engineers to take quick decisions.
\end{abstract}

Keywords: Six sigma quality level, control chart, process control, six sigma.

\section{Introduction}

The concept of 6 sigma was introduced by Motorola (1980) by the engineer Harry who analyzed variations in outcomes of the company's internal procedures and realized that by measuring variations it will be possible to improve the working of the system. The procedure was aimed at taking action to improve the overall performance. The general electronic company and allied signal started to adopt 6 sigma throughout the entire organization. The companies, which are practicing 6 sigma initiatives, are expected to produce 3.4 or less number of defects per million opportunities. Radhakrishnan (2009) suggested the construction of single sampling plan indexed through 6 sigma quality levels (SSQLs) based on intervened random effect Poisson distribution and weighted Poisson distribution as the base line distributions. Radhakrishnan and Balamurugan (2009a, 2009b, 2009c, 2010) suggested various 6 sigma based control charts such as average chart, chart for number of defectives, chart for number of defects and chart for average number of defect per unit in place of $\bar{X}$ chart, np chart, c - chart and u - chart suggested by Shewhart based on 3 sigma limits. Further Radhakrishnan and Sivakumaran (2008a, 2008b, 2008c, $2009 \mathrm{~d})$ used the concept of 6 sigma and constructed single, double and repetitive group sampling plans indexed through 6 sigma quality levels (SSQLs) with poisson distribution as the base line distribution. The control charts originated by Shewhart (1931) and Montgomery (2001) was based on 3 sigma control limits. If the same charts are used for the products of the companies which adopt 6 sigma initiatives in the process, then no point will fall outside the control limits because of the improvement in the quality. So a separate control chart is required to monitor the outcomes of the companies, which adopt 6 sigma initiatives. In this paper LSL,

an attempt is made to construct a 6 sigma based eexponentially weighted moving average control chart and a suitable table is also constructed and presented for the engineers to take quick decisions.

\section{Concepts \& terminologies}

Upper specification limit (USL): It is the greatest amount specified by the producer for a process or product to have the acceptable performance.

Lower specification limit (LSL): It is the smallest amount specified by the producer for a process or product to have the acceptable performance.

Tolerance level (TL): It is the difference between USL and

$\mathrm{TL}=\mathrm{USL}-\mathrm{LSL}$

Process capability (Cp)

This is the ratio of tolerance level to six times standard deviation of the process.

$$
c_{p}=\frac{T L}{6 \sigma}=\frac{U S L-L S L}{6 \sigma}
$$

Width factor $\left(G_{6 \sigma}\right)$

The value of $G_{6 \sigma}$ is the usual $6 \sigma$ limits i.e. the value of 4.831 is obtained using $\mathrm{p}\left(\mathrm{z} \leq \mathrm{z}_{6 \sigma}\right)=1-\alpha_{1}, \alpha_{1}=3.4 \times 10^{-6}$ and $\mathrm{z}$ is a standard normal variate. There is an advantage in reducing the width of the limits by using a value of $G_{6 \sigma}$ between about 4.4 and 4.6 .

$$
\therefore G_{6 \sigma}=4.5
$$

\section{Constant factor $\left(\lambda_{6 \sigma}\right)$}

It is a constant, $0<\lambda \leq 1$ is used in six sigma initiatives. 
Table 1. Diameter measurement

\begin{tabular}{|c|c|}
\hline $\begin{array}{c}\text { Sub } \\
\text { group, i }\end{array}$ & $x_{i}$ \\
\hline 1 & 9.45 \\
2 & 7.99 \\
3 & 9.29 \\
4 & 11.66 \\
5 & 12.16 \\
6 & 10.18 \\
7 & 8.04 \\
8 & 11.46 \\
9 & 9.2 \\
10 & 10.34 \\
11 & 9.03 \\
12 & 11.47 \\
13 & 10.51 \\
14 & 9.4 \\
15 & 10.08 \\
16 & 9.37 \\
17 & 10.62 \\
18 & 10.31 \\
19 & 8.52 \\
20 & 10.84 \\
21 & 10.9 \\
22 & 9.33 \\
23 & 12.29 \\
24 & 11.5 \\
25 & 10.6 \\
26 & 11.08 \\
27 & 10.38 \\
28 & 11.62 \\
29 & 11.31 \\
30 & 10.52 \\
\hline & \\
\hline
\end{tabular}

Fig. 1. Comparison of the process: $3 \sigma$ limits \& control limits using 6 sigma initiatives

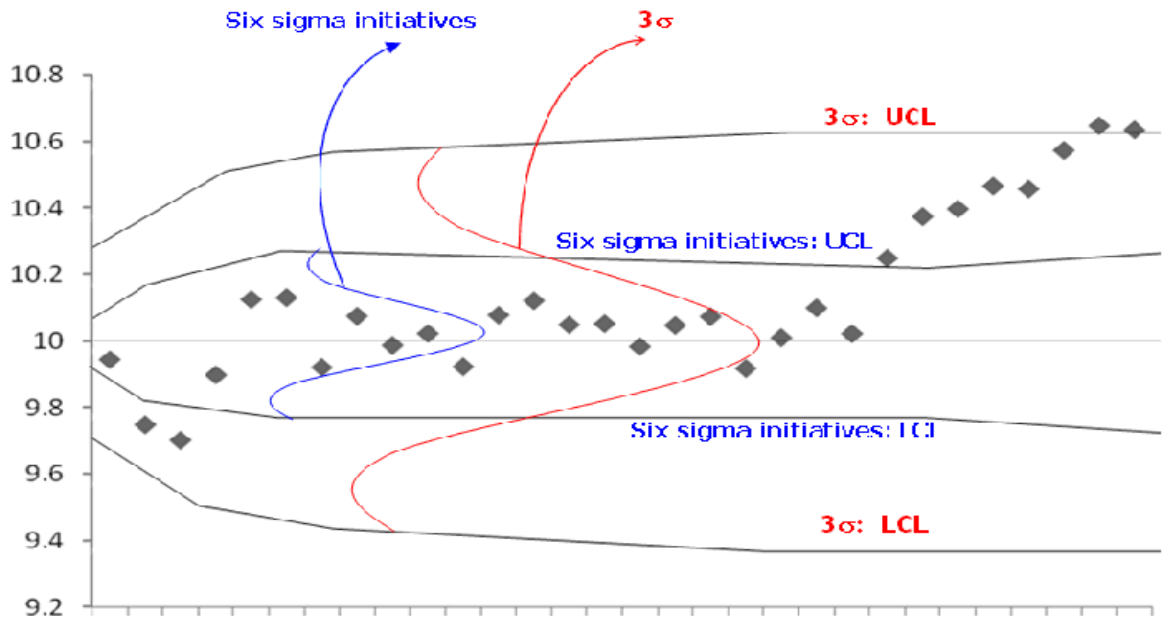

$122 \quad 3 \quad 4 \quad 5 \quad 6 \quad 7 \quad 8 \quad 9101112131415161718192021222324252627282930$
Table 2. Values of EWMA with each subgroup

\begin{tabular}{|c|c|c|}
\hline $\begin{array}{c}\text { Sub } \\
\text { group, } \mathrm{i}\end{array}$ & $X_{i}$ & EWMA, \\
\hline 1 & 9.45 & 9.94500 \\
2 & 7.99 & 9.74950 \\
3 & 9.29 & 9.70355 \\
4 & 11.66 & 9.89920 \\
5 & 12.16 & 10.12530 \\
6 & 10.18 & 10.13070 \\
7 & 8.04 & 9.921670 \\
8 & 11.46 & 10.07550 \\
9 & 9.2 & 9.98796 \\
10 & 10.34 & 10.02320 \\
11 & 9.03 & 9.92384 \\
12 & 11.47 & 10.07850 \\
13 & 10.51 & 10.12160 \\
14 & 9.4 & 10.04950 \\
15 & 10.08 & 10.05250 \\
16 & 9.37 & 9.98426 \\
17 & 10.62 & 10.04780 \\
18 & 10.31 & 10.07400 \\
19 & 8.52 & 9.91864 \\
20 & 10.84 & 10.01080 \\
21 & 10.9 & 10.09970 \\
22 & 9.33 & 10.02270 \\
23 & 12.29 & 10.24950 \\
24 & 11.5 & 10.37450 \\
25 & 10.6 & 10.39710 \\
26 & 11.08 & 10.46540 \\
27 & 10.38 & 10.45680 \\
28 & 11.62 & 10.57310 \\
29 & 11.31 & 10.64680 \\
30 & 10.52 & 10.63410 \\
\hline & & \\
\hline
\end{tabular}

Table 3. $\sigma_{6 \sigma}$ Values for a specified $C p \& T L$.

\begin{tabular}{|c|c|c|c|c|c|c|}
\cline { 1 - 5 } $\mathrm{TL}$ & \multirow{2}{*}{4.0} & 4.1 & 4.2 & 4.3 & 4.4 & 4.5 \\
\hline 1.0 & 0.67 & 0.68 & 0.7 & 0.71 & 0.73 & 0.75 \\
\hline 1.1 & 0.61 & 0.62 & 0.63 & 0.65 & 0.67 & 0.68 \\
\hline 1.2 & 0.56 & 0.57 & 0.58 & 0.60 & 0.61 & 0.63 \\
\hline 1.3 & 0.51 & 0.53 & 0.54 & 0.55 & 0.56 & 0.58 \\
\hline 1.4 & 0.48 & 0.49 & 0.5 & 0.51 & 0.52 & 0.54 \\
\hline 1.5 & 0.44 & 0.46 & 0.47 & 0.48 & 0.49 & 0.50 \\
\hline 1.6 & 0.42 & 0.43 & 0.44 & 0.45 & 0.46 & 0.47 \\
\hline 1.7 & 0.39 & 0.40 & 0.41 & 0.42 & 0.43 & 0.44 \\
\hline 1.8 & 0.37 & 0.38 & 0.39 & 0.40 & 0.41 & 0.42 \\
\hline 1.9 & 0.35 & 0.36 & 0.37 & 0.38 & 0.39 & 0.39 \\
\hline 2.0 & 0.33 & 0.34 & 0.35 & 0.36 & 0.37 & 0.38 \\
\hline 2.1 & 0.32 & 0.33 & 0.33 & 0.34 & 0.35 & 0.36 \\
\hline 2.2 & 0.30 & 0.31 & 0.31 & 0.33 & 0.33 & 0.34 \\
\hline 2.3 & 0.29 & 0.30 & 0.30 & 0.31 & 0.32 & 0.33 \\
\hline 2.4 & 0.28 & 0.28 & 0.29 & 0.30 & 0.31 & 0.31 \\
\hline 2.5 & 0.27 & 0.27 & 0.28 & 0.29 & 0.29 & 0.30 \\
\hline
\end{tabular}

Construction of six sigma based control chart for the number of defectives

For a specified $T L$ and $C p$ of the process, the value of $\sigma$ (termed as $\sigma_{6 \sigma}$ ) is calculated from $c_{p}=\frac{T L}{6 \sigma}$ using a $\mathrm{C}$ program and presented in Table 3 for various combinations of TL and $\mathrm{Cp}$. The modified control limits for six sigma based exponentially weighted moving average control chart is constructed as

$$
\mathrm{UCL}_{6 \sigma}=\mu_{0}+\mathrm{G}_{6 \sigma} \sigma_{6 \sigma} \sqrt{\frac{\lambda_{6 \sigma}}{\left(2-\lambda_{6 \sigma}\right)}\left[1-\left(1-\lambda_{6 \sigma}\right)^{2 i}\right]}
$$

Central Line, $\mathrm{CL}_{6 \sigma}=\mu_{0}$

$$
\mathrm{LCL}_{6 \sigma}=\mu_{0}-\mathrm{G}_{6 \sigma} \sigma_{6 \sigma} \sqrt{\frac{\lambda_{6 \sigma}}{\left(2-\lambda_{6 \sigma}\right)}\left[1-\left(1-\lambda_{6 \sigma}\right)^{2 i}\right]}
$$

\section{Conditions for application}

1) Human involvement should be less in the manufacturing process.

2) The company adopts six sigma quality initiatives in its processes.

Eg., (Montgomery, 2001).

Piston rings for an automotive engine are produced by a forging process. We wish to establish statistical control of the inside diameter of the rings manufactured by this process using cumulative sum control chart. Thirty subgroups have been taken when we think the process is in control. The inside diameter measurement data from these subgroups are shown in Table 1.
Research article Clndian Society for Education and Environment (iSee)
"Six sigma" http://www.indjst.org
Radhakrishnan \& Balamurugan Indian J.Sci.Technol. 
Calculation of exponentially weighted moving average control chart (EWMA)

Control limits $(3 \sigma)$ for the exponentially weighted moving average control chart

The exponentially weighted moving average is defined as $z_{i}=\lambda x_{i}+(1-\lambda) z_{i-1}$, where $\lambda=0.1$ and $\mu_{0}=10$

The control limits suggested by Roberts (1959) based on

$3 \sigma$ limits is $\mu_{0} \pm L \sigma \sqrt{\frac{\lambda}{(2-\lambda)}\left[1-(1-\lambda)^{2 i}\right]}$

For period $\mathrm{i}=1$,

$\mathrm{UCL}_{3 \sigma}=\mu_{0}+\mathrm{L} \sigma \sqrt{\frac{\lambda}{(2-\lambda)}\left[1-(1-\lambda)^{2 i}\right]}$
$=10+2.7(1) \sqrt{\frac{0.1}{(2-0.1)}\left[1-(1-0.1)^{2(1)}\right]}=10.27$

Central Line, $\mathrm{CL}_{3 \sigma}=\mu_{0}=10$

$\mathrm{LCL}_{3 \sigma}=\mu_{0}-\mathrm{L} \sigma \sqrt{\frac{\lambda}{(2-\lambda)}\left[1-(1-\lambda)^{2 i}\right]}$

$=10-2.7(1) \sqrt{\frac{0.1}{(2-0.1)}\left[1-(1-0.1)^{2(1)}\right]}=9.73$

For period $\mathrm{i}=30$,

$\mathrm{UCL}_{3 \sigma}=\mu_{0}+\mathrm{L} \sigma \sqrt{\frac{\lambda}{(2-\lambda)}\left[1-(1-\lambda)^{2 i}\right]}$

$=10+2.7(1) \sqrt{\frac{0.1}{(2-0.1)}\left[1-(1-0.1)^{2(30)}\right]}=10.62$

Central Line, $\mathrm{CL}_{3 \sigma}=\mu_{0}=10$

$\mathrm{LCL}_{3 \sigma}=\mu_{0}-\mathrm{L} \sigma \sqrt{\frac{\lambda}{(2-\lambda)}\left[1-(1-\lambda)^{2 i}\right]}$

$=10-2.7(1) \sqrt{\frac{0.1}{(2-0.1)}\left[1-(1-0.1)^{2(30)}\right]}=9.38$

and the control limits can be calculated for any $\mathrm{i}$ from 1 to 30 (Table 2).

It is found from the limits that the sample numbers $29^{\text {th }}$ and $30^{\text {th }}$ goes above the upper control limit. Therefore the process does not exhibit statistical control and need for rework operations to change a certain quality characteristic $\mathrm{f}$ the product.

Exponentially weighted moving average control limits based on six sigma initiatives

For a given $\mathrm{TL}=4.3 \& \mathrm{Cp}=2.5$, it is found from the

Table 3 the value of $\sigma_{6 \sigma}$ is 0.29 . The 6 sigma based exponentially weighted moving average control chart for a specified $T L$, and $\sigma_{6 \sigma}$ is $\mu_{0} \pm G_{6 \sigma} \sigma_{6 \sigma} \sqrt{\frac{\lambda_{6 \sigma}}{\left(2-\lambda_{6 \sigma}\right)}\left[1-\left(1-\lambda_{6 \sigma}\right)^{2 i}\right]}$ with

$\mathrm{UCL}_{6 \sigma}=\mu_{0}+\mathrm{G}_{6 \sigma} \sigma_{6 \sigma} \sqrt{\frac{\lambda}{(2-\lambda)}\left[1-(1-\lambda)^{2 i}\right]}$

$=10+(4.5 \times 0.29) \sqrt{\frac{0.1}{(2-0.1)}\left[1-(1-0.1)^{2(1)}\right]}$

$=10.13$

Central Line, $\mathrm{CL}_{6 \sigma}=\mu_{0}=10$

$\mathrm{LCL}_{6 \sigma}=\mu_{0}-\mathrm{G}_{6 \sigma} \sigma_{6 \sigma} \sqrt{\frac{\lambda}{(2-\lambda)}\left[1-(1-\lambda)^{2 i}\right]}$
$=10-(4.5 \times 0.29) \sqrt{\frac{0.1}{(2-0.1)}\left[1-(1-0.1)^{2(1)}\right]}$

$=9.87 \quad$ for $\mathrm{i}=1$

$\mathrm{UCL}_{6 \sigma}=\mu_{0}+\mathrm{G}_{6 \sigma} \sigma_{6 \sigma} \sqrt{\frac{\lambda}{(2-\lambda)}\left[1-(1-\lambda)^{2 i}\right]}$

$=10+(4.5 \times 0.29) \sqrt{\frac{0.1}{(2-0.1)}\left[1-(1-0.1)^{2(30)}\right]}=10.30$

Central Line, $\mathrm{CL}_{6 \sigma}=\mu_{0}=10$

$\mathrm{LCL}_{6 \sigma}=\mu_{0}-\mathrm{G}_{6 \sigma} \sigma_{6 \sigma} \sqrt{\frac{\lambda}{(2-\lambda)}\left[1-(1-\lambda)^{2 i}\right]}$

$=10-(4.5 \times 0.29) \sqrt{\frac{0.1}{(2-0.1)}\left[1-(1-0.1)^{2(30)}\right]}$

$=9.70 \quad$ for $\mathrm{i}=30$

and the control limits can be calculated for any $i$ from 1 to 30.

It is clear from the Fig. 1 that the process is out of control, since the sample numbers $23^{\text {rd }}, 24^{\text {th }}, 25^{\text {th }}, 26^{\text {th }}$, $27^{\text {th }}, 28^{\text {th }}, 29^{\text {th }}$ and $30^{\text {th }}$ goes above the upper control limit and the sample numbers $2^{\text {nd }}$ and $3^{\text {rd }}$ goes below the lower control limit and need for rework operations to change a certain quality characteristic of the product. The comparison of the process using $3 \sigma$ control limits and the six sigma initiatives for the exponentially weighted moving average is explained below.

\section{Conclusion}

In this paper, a procedure is given to construct a 6 sigma based eexponentially weighted moving average control chart with an example. In the EWMA chart based on 6 sigma initiatives when compared to the EWMA chart based on 3 sigma limits it is very clear that when the process is centered with reduced variation many points fall outside the control limits, which indicate that the process is not in the level it was expected. So a correction in the process is very much required to reduce the variations. The charts suggested in this paper will be 
very useful for the companies practicing six sigma initiatives in their process. These charts will replace the existing $3 \sigma$ control charts in future when all the companies started implementing 6 sigma initiatives in their organization.

\section{References}

1. Montgomery DC (2001) Introduction to statistical quality control. $3^{\text {rd }}$ edn., John Wiley \& Sons, Inc., NY.

2. Radhakrishnan $R$ (2009) Construction of six sigma based sampling plans. D. Sc. Thesis submitted to Bharathiar Univ., Coimbatore, India.

3. Radhakrishnan R and Balamurugan P (2009a) Trends in information technology and business intelligence. Excel India Publ., New Delhi.

4. Radhakrishnan R and Balamurugan $P$ (2009b) International marketing in Asia pacific: Issues and challenges. McMillan Publ., New Delhi.

5. Radhakrishnan $R$ and Balamurugan $P$ (2009c) Innovative practices in management. Himalaya Publ.,, New Delhi.

6. Radhakrishnan $R$ and Balamurugan $P$ (2010) Industrial engineering and operations management. Bangladesh, Society of mechanical engineers, Dhaka, Bangladesh.
7. Radhakrishnan R and Sivakumaran PK (2008a) Construction and selection of 6 sigma sampling plan indexed through 6 sigma quality level. Int. J. Statistics Sys. 3(2), 153-159.

8. Radhakrishnan R and Sivakumaran PK (2008b) Construction of 6 sigma repetitive group sampling plan, Int. J. Math. Comp. 1(8), 75-83.

9. Radhakrishnan R and Sivakumaran PK (2008c) Construction and selection of conditional double sampling plan indexed through 6 sigma quality levels. Srilankan J. Appl. Statistics. 9, 74-83.

10.Radhakrishnan R and Sivakumaran PK (2009d) Construction of double sampling plans through 6 sigma quality levels. Proc. of the IEEE $2^{\text {nd }}$ Int. Joint Conf. Comp. Sci. Optimization (IEEECSO2009), Sanya, Hainan, China, 1027-1030.

11.Roberts SW (1959) Control chart tests based on geometric moving averages. Technometrics. Vol. 1.

12.Shewhart WA (1931) Economic control of quality of manufactured product. Van Nostrand, NY. 